\title{
Special issue on novel management tactics for the Western flower thrips
}

\author{
Yulin Gao ${ }^{1}$. Stuart R. Reitz ${ }^{2}$
}

Received: 29 April 2020 / Revised: 12 May 2020 / Accepted: 19 May 2020 / Published online: 28 May 2020

c) Springer-Verlag GmbH Germany, part of Springer Nature 2020

\begin{abstract}
The Western flower thrips (WFT), Frankliniella occidentalis, is a major threat to a wide range of agricultural crops and rapidly spreads throughout the world. Its international importance as a pest has led to tremendous growth in our knowledge of its biology, ecology, and novel approaches for its management. Unfortunately, the literature on WFT is widely dispersed and many researchers, extension specialists, and IPM practitioners are only now becoming aware of WFT, which has meant that management programs are still reliant on intense insecticide use, especially in recently invaded regions. Due to the current high demand in effective and sustainable control tactics for this pest, Journal of Pest Science dedicates a special issue to WFT. This special issue provides a consolidated review of WFT biology and ecology and helps to highlight alternative and novel management techniques to effectively controlling this pest in the future.
\end{abstract}

Keywords Western flower thrips $\cdot$ Biology and ecology $\cdot$ Novel management $\cdot$ IPM

Western flower thrips (WFT), Frankliniella occidentalis (Pergande) (Thysanoptera: Thripidae), is a highly polyphagous herbivore and economically important pest of many crops globally (Kirk and Terry 2003; Morse and Hoddle 2006; Reitz 2009). Economic damage results directly through feeding and oviposition, and indirectly through transmission of plant pathogenic viruses in the genus Orthotospovirus (Tospoviridae) (Reitz et al. 2020). The sum of its biological characteristics, including its polyphagy, small size, short developmental times, high reproductive rate, cryptic life style habits, and competitive ability, have combined to promote this species to its current dominant global pest status (Gao and Reitz 2017; Reitz et al. 2020).

Frankliniella occidentalis first arose as one of the world's most important invasive pests of horticultural and

Yulin Gao

gaoyulin@caas.cn

$\bowtie$ Stuart R. Reitz

Stuart.Reitz@oregonstate.edu

1 State Key Laboratory for Biology of Plant Diseases and Insect Pests, Institute of Plant Protection, Chinese Academy of Agricultural Sciences, Beijing 100193, People's Republic of China

2 Department of Crop and Soil Sciences, Malheur Experiment Station, Oregon State University, Ontario, OR 97914, USA agronomic crops during the 1970s-1980s (Reitz 2009). The recent worldwide growth in the commercial movement of plant materials has allowed for a rapid expansion of its range throughout North America, South America, Australia, Oceania, Africa, Europe, and Asia (Gao et al. 2012). Even in areas where WFT has long been established, it is becoming more prevalent and damaging (Broughton and Harrison 2012).

The economic importance of WFT has generated a tremendous amount of research on its biology, ecology, and management (Reitz 2009; Reitz et al. 2020). As a result, a variety of management tactics for WFT have been explored, the most common of which has been the use of chemical insecticides (Gao et al. 2012). Unfortunately, reliance on insecticides has proven not to be an effective or sustainable approach owing to WFT propensity for evolving resistance to insecticides and their cryptic nature that reduces their exposure to insecticide sprays (Fig. 1). Therefore, effective management programs are ones that integrate diverse tactics, and the tactics themselves often affect WFT populations in multiple, interacting ways. While these interactions confound a simple categorization of approaches, they are critical to successful management.

As guest editors, we are pleased to present 12 papers regarding the biology, ecology, and management of WFT in this special issue of the Journal of Pest Science. These 


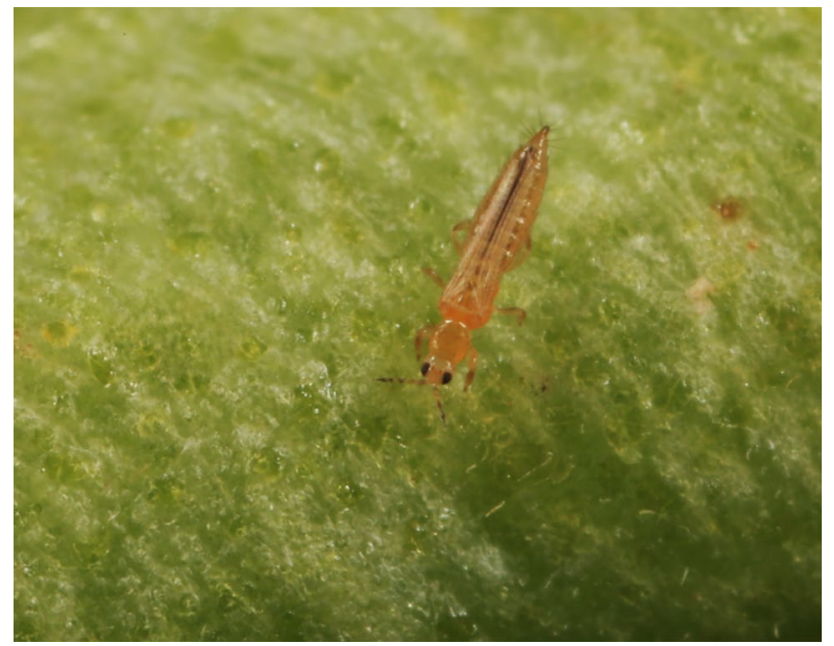

Fig. 1 F. occidentalis adult feeding on cowpea. Photograph credit: Yulin Gao

articles contribute to our current understanding of the biology of this species, provide guidance for countries to enhance their management of WFT, and offer insight into how climate change may affect our interactions with WFT.

The critical topic of how WFT interact with host plants is examined in three articles. Sampson et al. (2020) reveal how WFT utilize crop and weed hosts to overwinter successfully. Avellaneda et al. (2020) identify volatile organic compounds from roses that WFT may use as host location cues. Alternatively, Escobar-Bravo et al. (2020) demonstrate how plant defenses that make plants less suitable as hosts are mediated by environmental factors, such as ultraviolet light.

Several contributions examine interspecific competition among WFT and other thrips species, and the effect of these interactions on population dynamics. Wu et al. (2020) summarize current knowledge on competitive interactions between WFT and locally present thrips species, and how these interactions affect the invasiveness of WFT. Chen et al. (2020) demonstrate that Orthotospovirus infection of a host plant confers a competitive advantage to WFT against Thrips palmi. Qian et al. (2020) describe the impacts of elevated $\mathrm{CO}_{2}$ on a WFT host plant and its succeeding beneficial effects on WFT physiology and life history traits. Cao et al. (2020) found similar results for WFT, but showed that elevated $\mathrm{CO}_{2}$ levels are detrimental to Thrips hawaiiensis, which could affect interspecific interactions among these species in the future.

Given the extensive use of insecticides in attempts to manage WFT, several papers examine insecticide resistance and its impact on WFT management. Gao et al. (2020) assessed variation within and among thrips species in resistance to the commonly used insecticide, spinetoram. Although WFT populations did not always possess the greatest levels of resistance to spinetoram. Wan et al. (2020), in a separate study, demonstrate how insecticide resistance increases the competence of WFT to acquire and transmit Tomato spotted wilt orthotospovirus. These findings support the need for improved management tactics for WFT. $\mathrm{Li}$ et al. (2020) demonstrate the efficacy of a novel strain of Metarhizium anisopliae. Zhang et al. (2020) also show the compatibility of another fungal pathogen with predatory mites for the control of WFT. Lin et al. (2020) then provide an approach that successfully integrates the use of a conventional insecticide with releases of a predatory bug for management of WFT.

We are thankful to the numerous experts on F. occidentalis who responded to our invitation to contribute to this special issue and submitted their work for publication. All manuscripts were processed through the peer-review system of the journal, and we are thus grateful to journal editor in chief, Michael Traugott who agreed to publish this special issue. We are also grateful to the reviewers whose generous commitment of time and effort in critiquing the contributions that now comprise this Special Issue on novel management tactics for the western flower thrips. We thank the National Key Research and Development Program of China (2018YFD0200802) for its support of the publication of this special issue.

\section{Compliance with ethical standards}

Conflict of interest Authors Yulin Gao and Stuart Reitz declare that they have no conflict of interest.

Ethical approval All applicable international, national, and/or institutional guidelines for the care and use of animals were followed.

\section{References}

Avellaneda J, Diaz M, Coy-Barrera E, Rodriguez D, Osorio C (2020) Rose volatile compounds allow the design of new control strategies for the western flower thrips (Frankliniella occidentalis). J Pest Sci. https://doi.org/10.1007/s10340-019-01131-7

Broughton S, Harrison J (2012) Evaluation of monitoring methods for thrips and the effect of trap colour and semiochemicals on sticky trap capture of thrips (Thysanoptera) and beneficial insects (Syrphidae, Hemerobiidae) in deciduous fruit trees in Western Australia. Crop Prot 42:156-163

Cao Y, Yang H, Wang LJ, Li J, Wang C, Gao YL, Li C (2020) Effect of elevated $\mathrm{CO} 2$ on the population development of the invasive species Frankliniella occidentalis and native species Thrips hawaiiensis and activities of their detoxifying enzymes. J Pest Sci. https ://doi.org/10.1007/s10340-020-01224-8

Chen Y, Zheng X, Wei H, Chen YD, Zheng KY, Mu Y, Zhao XY, Zhao LH, Gao YL, Zheng LM, Zhang J (2020) A plant virus mediates interspecific competition between its insect vectors in Capsicum апnиит. J Pest Sci. https://doi.org/10.1007/s10340-020-01211-z 
Escobar-Bravo R, Nederpel C, Naranjpo S, Kim HK, Rodriguez-Lopez MJ, Chen G, Glauser G, Leiss KA, Klinkhamer PGL (2020) Ultraviolet radiation modulates both constitutive and inducible plant defenses against thrips but is dose- and plant genotype-dependent. J Pest Sci. https://doi.org/10.1007/s10340-019-01166-w

Gao YL, Reitz SR (2017) Emerging themes in our understanding of species displacements. Annu Rev Entomol 62:165-183

Gao YL, Lei ZR, Reitz SR (2012) Western flower thrips resistance to insecticides: detection, mechanisms, and management strategies. Pest Manag Sci 68:1111-1121

Gao YF, Gong YJ, Cao LJ, Chen JC, Gao YL, Mirab-balou M, Chen M, Hoffman AA, Wei SJ (2020) Geographical and interspecific variation in susceptibility of three common thrips species to the insecticide, spinetoram. J Pest Sci. https://doi.org/10.1007/s 1034 0-019-01128-2

Kirk WDJ, Terry LI (2003) The spread of the Western flower thrips, Frankliniella occidentalis. Agr For Entomol 5:301-310

Li J, Xie JQ, Zeng DY, Xia YX, Peng GX (2020) Effective control of Frankliniella occidentalis by Metarhizium anisopliae CQMa421 under field conditions. J Pest Sci. https://doi.org/10.1007/s1034 0-020-01223-9

Lin QC, Chen H, Babendreier Zhang JP, Zhang F, Dai XY, Sun ZE, Shi ZP, Dong XL, Wu GA, Yu Y, Li Zheng, Zhai YF (2020) Improved control of Frankliniella occidentalis on greenhouse pepper through integration of Orius sauteri and neonicotinoid insecticides. J Pest Sci. https://doi.org/10.1007/s10340-020-01198-7

Morse JG, Hoddle MS (2006) Invasion biology of thrips. Annu Rev Entomol 51:67-89

Qian L, Huang ZJ, Liu XW, Li CX, Gao YL, Gui FR, Chang XL, Chen FJ (2020) Effect of elevated CO2 on interactions between the host plant Phaseolus vulgaris and the invasive western flower thrips. J
Pest Sci, Frankliniella occidentalis. https://doi.org/10.1007/s1034 0-020-01208-8

Reitz SR (2009) Biology and ecology of the western flower thrips (Thysanoptera: Thripidae): the making of a pest. Florida Entomol 92:7-13

Reitz SR, Gao YL, Kirk WDJ, Hoddle MS, Leiss KA, Funderburk JE (2020) Invasion biology, ecology, and management of the western flower thrips. Annu Rev Entomol 65:17-37

Sampson C, Bennison J, Kirk WDJ (2020) Overwintering of the western flower thrips in outdoor strawberry crops. J Pest Sci. https:// doi.org/10.1007/s10340-019-01163-Z

Wan YR, Zheng XB, Xu BY, Xie W, Wang SL, Zhang YJ, Zhou XG, Wu QJ (2020) Insecticide resistance increases the vector competence: a case study in Frankliniella occidentalis. J Pest Sci. https ://doi.org/10.1007/s10340-020-01207-9

Wu SY, Xing ZL, Ma TT, Xu DW, Li YY, Lei ZR, Gao YL (2020) Competitive interaction between Frankliniella occidentalis and locally present thrips species: a global review. J Pest Sci. https:// doi.org/10.1007/s10340-020-01212-y

Zhang XR, Wu SY, Reitz SR, Gao YL (2020) Simultaneous application of entomopathogenic Beauveria bassiana granules and predatory mites Stratiolaelaps scimitus for control of western flower thrips, Frankliniella occidentalis. J Pest Sci. https://doi.org/10.1007/ s10340-020-01227-5

Publisher's Note Springer Nature remains neutral with regard to jurisdictional claims in published maps and institutional affiliations. 